\title{
Pendampingan Komunitas Pembatik Melalui Pelatihan Alih Pengetahuan Membatik dengan Material Berbasis Kearifan Lokal
}

\author{
Ariesa Pandanwangi ${ }^{1}$, Ida $^{2}$, Olga Catherina Pattipawaej ${ }^{3}$ dan Erwani Merry Sartika ${ }^{4}$ \\ ${ }^{1}$ Program Studi Seni Rupa Murni, Fakultas Seni Rupa dan Desain Universitas Kristen Maranatha \\ ${ }^{2}$ Program Studi Manajemen, Fakultas Ekonomi Universitas Kristen Maranatha \\ ${ }^{3}$ Program Studi Teknik Sipil, Fakultas Teknik Universitas Kristen Maranatha \\ ${ }^{4}$ Program Studi Teknik Elektro, Fakultas Teknik Universitas Kristen Maranatha \\ ariesa.pandanwangi@maranatha.edu,ida.wijaya777@gmail.com, \\ olga.pattipawaej@gmail.com, erwanimerry@gmail.com
}

\begin{tabular}{l|l|l|l|l|l} 
Received : $\quad$ Jan $5^{\text {th }} 2019$ & Revised $\quad: \quad$ March $3^{\text {th }} 2019$ & Accepted $\quad: \quad$ May $3^{\text {th }} 2019$
\end{tabular}

\begin{abstract}
Indonesia is very rich in local wisdom, various types of plants can be processed into batik materials, one of which is tamarind tree which has not been widely known by many people. Tamarind seeds can be processed into a kind of cold wax, not hot wax. In the practice of traditional batik, this material is then used in community service activities with the aim of introducing how to make batik through batik workshop using cold wax easily and environmentally friendly. Participants in this workshop were foreign students and other people by using lectures method, batik demonstrations, and batik practices. To test the success of participants in batik knowledge and practice, the researcher used paired samples test. Based on the analysis, it can be said that there are differences in the knowledge of participants before and after community service activities. The aim of assistance was achieved because the transfer knowledge was successful, supported by the results of the trainer's questionnaire evaluation in terms of mastery of the material, clarity of material delivery, and appropriateness of time allocation.
\end{abstract}

Keywords: Worker in Batik, Tamarind Tree, Cold Wax

\section{Pendahuluan}

Batik Sebagai warisan budaya dunia telah memberikan peluang bagi masyarakat untuk mengembangkan bahkan menciptakan batik yang baru ${ }^{1}$. Penggunaan material lokal, terutama oleh masyarakat tradisional di berbagai daerah, tumbuh sebagai filosofi kearifan lokal, mendekatkan keperluan hidup sehari-hari dengan lingkungan alam sekitarnya ${ }^{2}$. Pernyataan tersebut menegaskan bahwa material lokal dekat dengan kehidupan masyarakat, sehingga memudahkan mereka untuk dapat menggunakannya. Sebagai contoh di Pulau Jawa banyak ditanam pohon asam Jawa, produknya banyak digunakan sebagai penyedap masakan, sedangkan bijinya diolah dengan cara dikeringkan dan dibuat menjadi semacam bubuk/tepung. Tepung ini dapat dimanfaatkan untuk membuat kue atau roti ${ }^{3}$. Tetapi ada satu hal yang tak banyak diketahui oleh banyak orang, yaitu biji (2013)

${ }^{1}$ Wahyu Tri Atmojo, “JURNAL Pengabdian Kepada Masyarakat Vol. 19 Nomor 71 Tahun XIX Maret $2013 ” 19$

2 Asikin Hasan, 'Seni Rupa Kontemporer Indonesia 'LALU, KINI [Budaya Bendawi]' Di Brussels Dan Antwerp, Belgia," Press Release : Pameran "L ALU, KINI” Dalam Rangka Europalia Arts Festival Indonesia 2017, 2017.

${ }^{3}$ M.Pd Dra Tity Soegiarty, Teknik Serti (Serti Technique) Dalam Pembelajaran Batik. Tulis Di Jurusan Pendidikan Seni Rupa FPBS UPI, 2008.

Volume 3, Number 1, Mei 2019|68 
yang sudah menjadi tepung dapat dimanfaatkan sebagai pengganti malam panas dalam membatik. Bahkan sentra pembatikanpun juga langka yang mengetahui hal ini. Uniknya justru material ini banyak dijual di daerah Pekalongan, Tasikmalaya yang merupakan area pembatikan. Terlepas dari penggunaan material alternatif untuk membatik, peran perempuan dalam mengangkat potensi lokal ke atas selembar batik merupakan target yang akan menjadi topik pada paper ini.

Batik terus berkembang, ada teknik rintang tanpa malam atau lilin, dengan proses yang hampir sama dengan membatik pada umumnya, yang membedakan adalah penggunaan material untuk perintang. Keragaman proses pembuatannya merupakan salah satu munculnya batik modern. Batik Modern adalah batik yang diolah dengan teknik baru, dapat juga disebut sebagai batik kreasi baru. Proses pembuatan batik modern dihasilkan dari berbagai eksplorasi yang dilakukan oleh seniman batik, baik ekplorasi dalam media maupun teknik ${ }^{4}$.

Batik adalah seni tradisional yang populer di kalangan minoritas di Cina Barat Daya, yang ditandai dengan teknik kerajinan tangan yang unik dan pola alami. Karena efisiensi yang lebih rendah dan polusi teknik batik sebelumnya, industri batik sedang berjuang dan teknik simulasi batik sangat diperlukan. ${ }^{5}$

Untuk membudidayakan batik dengan menggunakan material berbasis kearifan lokal ini, maka tim pengabdian melakukan pendampingan kepada ibu-ibu dan remaja yang tergabung dalam Ikatan Kekeluargaan Perempuan Maranatha dan masyarakat sekitar Universitas Maranatha melalui program pertukaran budaya dan pelajar. Dengan demikian, maka melalui pengabdian ini diharapkan dapat membantu pemerintah dalam pelestarian batik dengan memanfaatkan material berbasis kearifan lokal sehingga dampingan menjadi paham dan dapat mempraktikkan cara membuat batik, serta mampu menggali gagasan kreatif yang dapat diimplementasikan di atas selembar kain batik dengan mudah dan menyenangkan.

\section{Metode}

Pendekatan klasikal dilakukan pada saat pemberian materi awal tentang batik. Selanjutnya peserta diberikan pemahaman mengapa penting menggunakan kearifan lokal, dan implementasinya dalam proses pembatikan. Agar pengabdian ini dapat mencapai tujuan maka metode yang dipergunakan dalam pengabdian ini adalah:

Pertama ceramah. Metode ini dipergunakan untuk menyampaikan konsep-konsep batik

\footnotetext{
${ }^{4}$ Niken Apriani, "Kecintaan Terhadap Batik Buat Niken Kembangkan Perintang Warna Dari Tepung Biji Asam," Tribunnews.Com, last modified 2017, http://www.tribunnews.com/nasional/2017/08/08/kecintaanterhadap-batik-buat-niken-kembangkan-perintang-warna-dari-tepung-biji-asam.

${ }^{5}$ Yangtao Yu et al., "Visualization of Batik Cloth Based on Diffusion," in 2016 International Conference on Virtual Reality and Visualization (ICVRV) (IEEE, 2016), 511-515.
} 
tradisional dan pengembangannya dengan menggunakan material kearifan lokal, agar dipahami dan meningkatkan wawasan para peserta pelatihan. Penggunaan metode ini dengan mempertimbangkan bahwa metode ceramah dapat dikombinasikan dengan olah demo, sehingga diharapkan materi yang disampaikan dengan cepat dapat dimengerti oleh peserta. Materi yang diberikan meliputi: Konsep batik tradisional, pengembangan material batik dengan menggunakan biji asam Jawa, dan implementasi pengembangan membatik diatas kain polyester.

Kedua demonstrasi. Metode yang dipergunakan dalam pengabdian ini adalah metode demontrasi yaitu trainer mendemontrasikan proses pembuatan gutta tamarind, lalu dipraktikan di atas kain polyester. Metode ini memperlihatkan proses kerja dari tahapan membatik. Peserta terlebih dahulu mengamati secara langsung cara membatik yang mudah dan menyenangkan. Demonstrasi dilakukan oleh instruktur di hadapan peserta yang masing-masing menggunakan pensil $2 \mathrm{~B}$ atau diperbolehkan langsung menggunakan gutta.

Ketiga Latihan dengan praktik membatik. Metode ini diberikan kepada peserta agar mereka dapat mempraktikkan cara membatik.

Berdasarkan metode ceramah, demonstrasi, dan latihan praktik membatik di atas, maka pengabdian pada masyarakat ini akan memberikan dampak sebagai berikut: (1) Meningkatnya keterampilan masyarakat dalam membuat batik yang sederhana, sehingga dimungkinkan peserta di kemudian hari dapat mengembangkan kreativitasnya melalui imajinasinya; dan (2) Kemampuan peserta dalam memahami proses membatik sangat bervariatif sehingga dari hasil pelatihan tampak ada yang tidak maksimal karena belum paham prosesnya.

Selanjutnya untuk mengetahui adanya alih pengetahuan dalam membatik maka dilakukan penyebaran kuesioner yang berisi pertanyaan mengenai pengetahuan membatik peserta. Pertanyaan kuesioner mengenai material kearifan lokal yang digunakan dalam membatik, alat yang digunakan dalam membatik lilin dingin, jenis kain yang digunakan, jenis tumbuhan yang digunakan dalam material membatik, cara mengolah material membatik, proses pembuatan membatik sederhana dan cara membuat pola batik. Setiap peserta mengisi pertanyaan kuesioner ini sebanyak dua kali yaitu sebelum praktik dan sesudah praktik membatik. Selain itu juga peserta memberikan penilaian terhadap trainer dari aspek penguasaan materi, kejelasan penyampaian materi, kemampuan menjawab pertanyaan, interaksi dengan peserta, relevansi materi dengan kebutuhan peserta dan kesesuaian alokasi waktu dengan beban materi yang diterima. Pengisian kuesioner dari aspek trainer dilakukan setelah pelatihan.

Metode yang digunakan untuk mengetahui perbedaan pengetahuan peserta sebelum dan sesudah pelatihan adalah dengan melakukan uji normalitas dengan One-Sample Kolmogorov-Smirnov Test. Jika Data berdistribusi normal maka alat pengujian yang digunakan adalah Paired Samples Test 


\section{ENGAGEMENT}

QurnalPengabdianKepadaMasyarakat

ISSN : 2579-8375 (Print)

ISSN : 2579-8391 (Online)
This work is licensed under a Creative Commons Attribution-ShareAlike 4.0 International License.

sedangkan jika data tidak berdistribusi normal maka alat pengujian yang digunakan adalah Uji Wilcoxon.

\section{Hasil dan Diskusi}

Kegiatan ini dilaksanakan pada hari Selasa, 4 Desember 2018, dimulai dari pukul 09.00 dan selesai pada pukul 14.00. Peserta adalah masyarakat umum yang berasal dari program pertukaran budaya dan masyarakat umum seperti ditunjukkan pada Gambar 1 berikut ini.
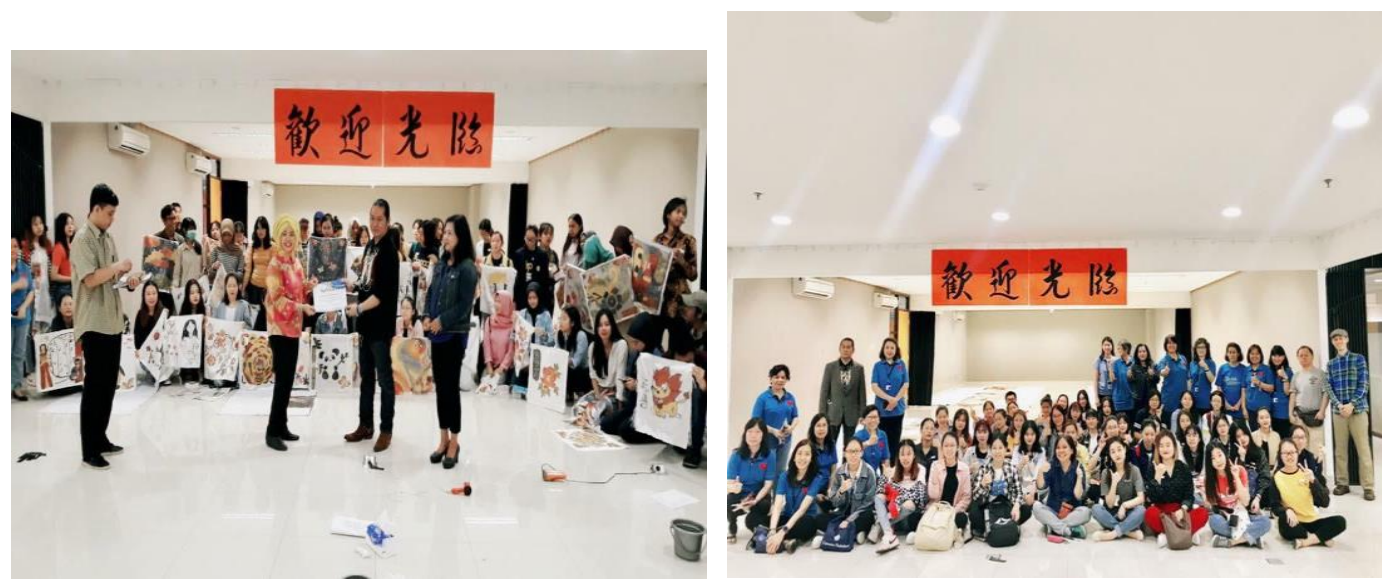

Gambar 1. Masyarakat umum dan pelajar dari pertukaran pelajar

Implementasi program ini dimulai dari pemberian materi tentang batik melalui pendekatan klasikal dilanjutkan dengan praktek membatik. Adapun tahap-tahap proses membatik dalam proses masyarakat sebagaimana berikut ini.

Tahap pertama, pembagian kelompok Untuk memudahkan dalam proses pendampingan, maka tim pendamping melakukan pembagian kelompok menjadi 10 kelompok besar dengan jumlah per kelompok terdiri atas 6-7 peserta, sebagaimana gambar 2.
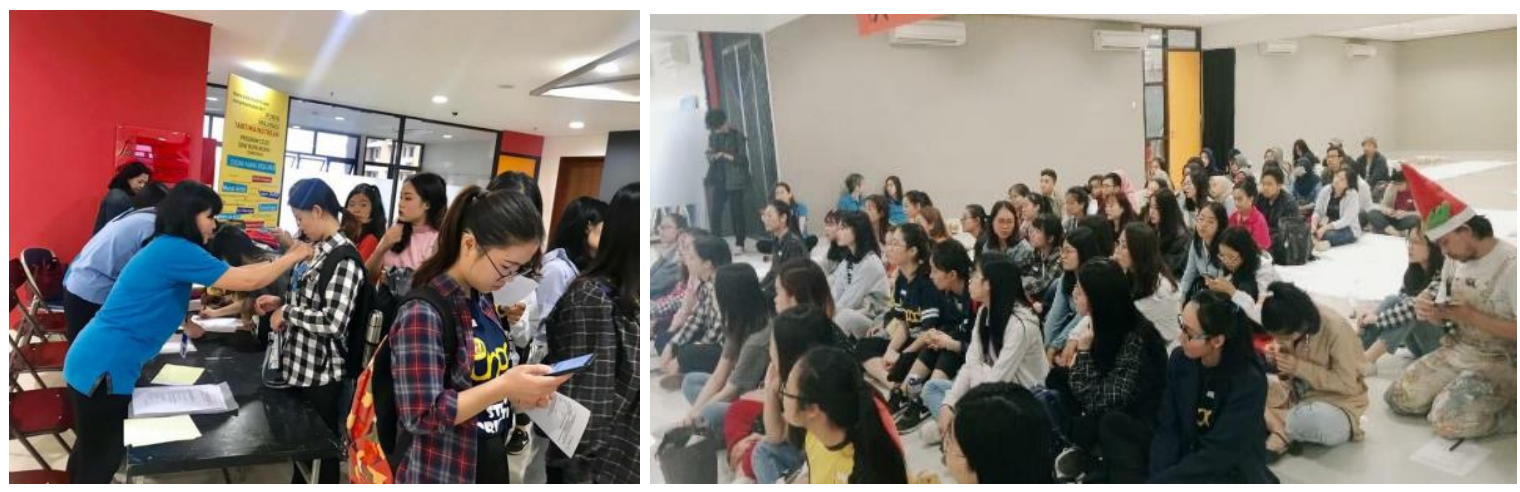

\section{Gambar 2. Pembagian Kelompok}

Langkah kedua, Demonstrasi Membatik. Setelah terbagi menjadi 10 kelompok, maka langkah selanjutnya adalah Trainer melakukan demo cara pembuatan gutta tamarind di depan peserta dengan langkah-langkah pengerjaan sebagai berikut: (1) Bubuk biji asam Jawa siapkan secukupnya;

Volume 3, Number 1, Mei 2019|71 


\section{ENGAGEMENT}

JurnalPengabdianKepadaMasyarakat

ISSN : 2579-8375 (Print)

ISSN : 2579-8391 (Online)
This work is licensed under a Creative Commons Attribution-ShareAlike 4.0 International License.

(2) Tambahkan mentega dan air panas; (3) Gutta siap dipergunakan untuk membatik; dan (4) Gutta masukan ke dalam plastik segitiga. Lebih jelasnya proses ini tergambar dalam Gambar 3. berikut ini:

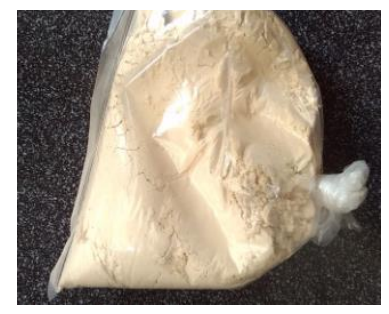

a. Bubuk biji asam Jawa siapkan secukupnya

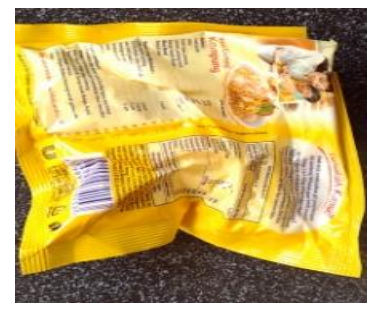

b. Tambahkan mentega dan airpanas

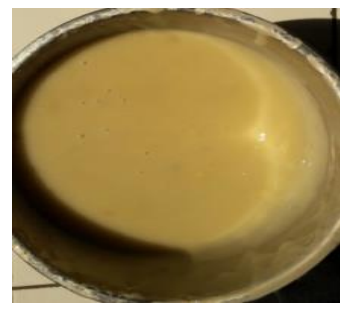

c. Gutta siap dipergunakan untuk membatik.

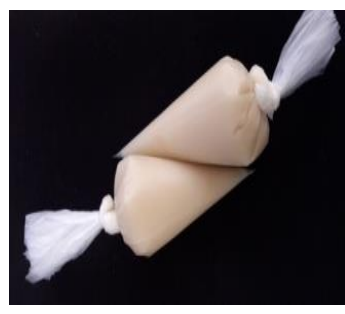

d. Gutta masukan ke dalam plastik segitiga

\section{Gambar 3. Langkah-langkah Pembuatan Malam Dingin $(a, b, c, d){ }^{6}$}

Selain itu, bahan-bahan dan alat (spanram, kain, dan hekter, kuas, pewarna, botol tempat cairan warna) juga disiapkan untuk membuat batik. Adapun langkah-langkahnya adalah dengan membentangkan Kain di atas spanram, kemudian pada keempat sisinya hekter hingga kain terbentang dengan kencang, kemudian dilanjutkan degan menyiapkan peralatan dan material pewarna. Bahan dan alat dalam tahap ini ditunjukkan pada Gambar 4 berikut ini:
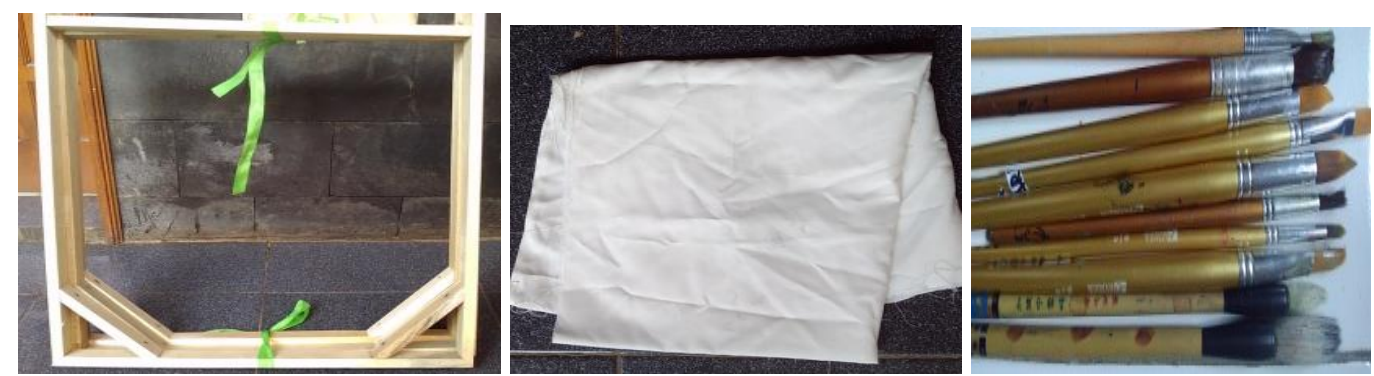

Spanram Kain Kuas
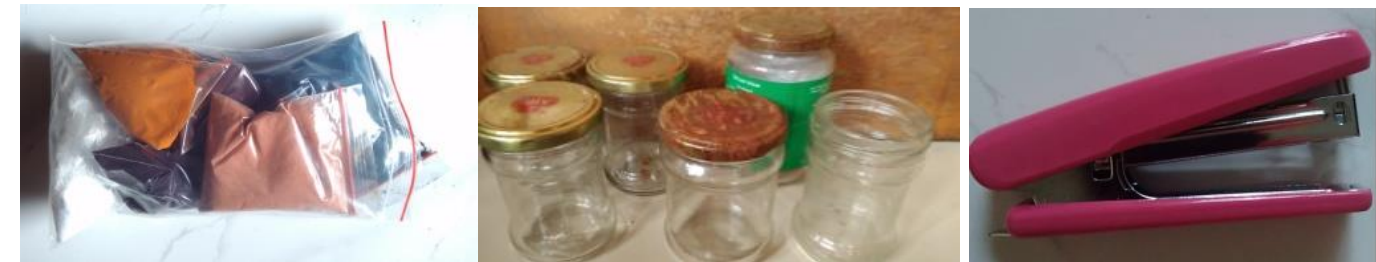

Pewarna Botol untuk tempat cairan warna Stepler

Gambar 4. Bahan-bahan dan alat untuk membuat batik

\footnotetext{
${ }^{6}$ Narasumber dari hasil wawancara: Niken Apriani. 2017 dan Foto oleh Ariesa Pandanwangi. 2017

${ }^{7}$ Foto oleh Ariesa Pandanwangi. 2017
} 


\section{ENGAGEMENT}

QurnalPengabdianKepadaMasyarakat

ISSN : 2579-8375 (Print)

ISSN : 2579-8391 (Online)
This work is licensed under a Creative Commons Attribution-ShareAlike 4.0 International License. CC BY SA

Langkah ketiga, Proses Praktikum. Pada tahap ini para trainer memulai dengan membagikan kain yang sudah dibentangkan di atas spanram, gutta, pewarna, dan kuas seperti ditunjukkan pada Gambar 5.
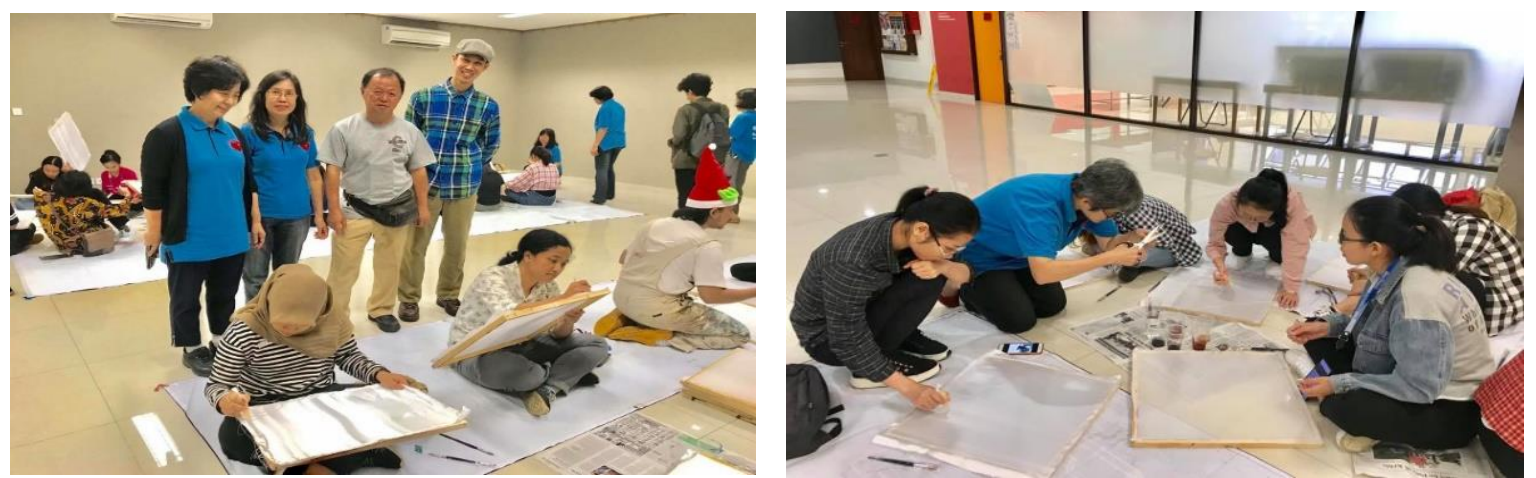

Gambar 5. Trainer membagi spanram, gutta, pewarna, dan kuas untuk masing-masing kelompok

Selanjutnya para peserta memulai dengan membuat sketsa dan dibubuhi gutta tamarin seperti ditunjukkan pada Gambar 6.
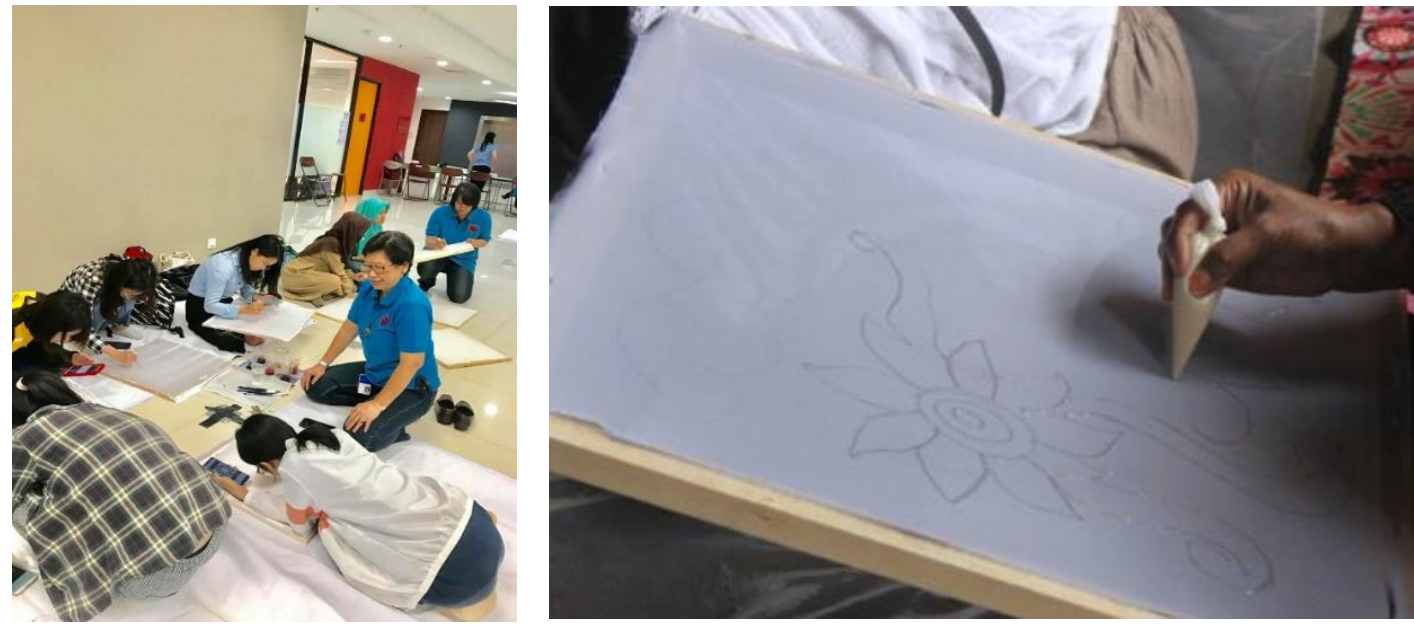

\section{Gambar 6. Peserta sedang mensketsa dan membubuhi gutta tamarin pada kain}

Selesai menggutta peserta menjemur di luar ruangan. Dalam proses ini, apabila cuaca kurang cerah maka bisa menggunakan hair dryer untuk mengeringkan gutta. Gutta yang sudah kering siap untuk diberikan warna pada objeknya. Manfaatnya gutta adalah sebagai pembatas pada warna yang satu dengan warna lainnya, agar tidak saling tercampur. Karena itu ketika mengguta garis yang dibuat tidak boleh terputus.

Tahap selanjutnya, setelah selesai diwarna jemur kembali hingga kering, kemudian disetrika dengan menggunakan pelapis kertas minyak. Fungsi kertas minyak agar gutta yang disetrika tidak lengket ke atas permukaan setrika. Setelah disetrika munculah warna yang sebenarnya seperti ditunjukkan

Volume 3, Number 1, Mei 2019|73 
pada Gambar 7.

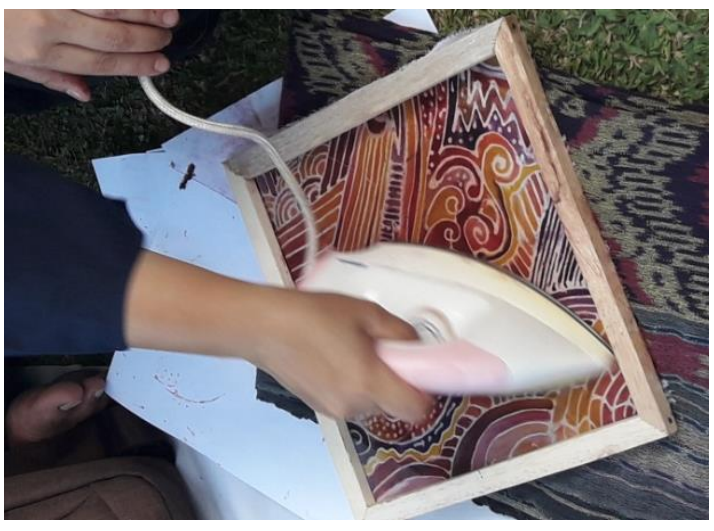

\section{Gambar 7. Batik malam dingin disetrika}

Apabila sudah disetrika, kemudian para peserta mencuci hingga bersih kain yang telah disetrika. Fungsi dari pencucian ini untuk melorotkan gutta, sehingga akan menampakkan bekas guratan gutta layaknya batik tradisional seperti tampak pada Gambar 8.

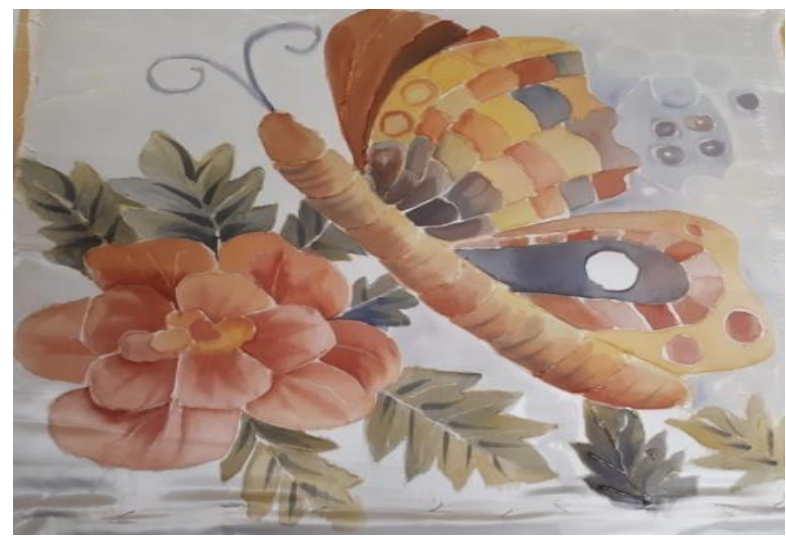

\section{Gambar 8. Batik yang telah disetrika dan dicuci}

Dari hasil proses pengabdian di atas, maka didapatkan hasil pengabdian bebagai karyakarya lukis batik yang dibuat oleh remaja usia 20-26 tahun. Hasil karya tersebut kemudian di presentasikan dengan cara didisplay dan dibahas bersama-sama sebagai bagian dari evaluasi.

Peserta mengikuti proses tahapan dalam membatik dari awal membuat sketsa, menggutta, mengeringkan gutta, memberi warna, mengeringkan warna, hingga menyetrika untuk memunculkan warna. Adapun sampel yang diambil ada 11 karya lukis batik berukuran 60 x $60 \mathrm{~cm}$ ditunjukkan pada Gambar 10, dengan indikator sampel dengan terselesaikannya objek yang dibuat di atas polyester. 


\section{ENGAGEMENT}

JurnalPengabdian KepadaMasyarakat

ISSN : 2579-8375 (Print)

ISSN : 2579-8391 (Online)
This work is licensed under a Creative Commons Attribution-ShareAlike 4.0 International License.

CC BY SA

\section{Sampel Lukis Batik}
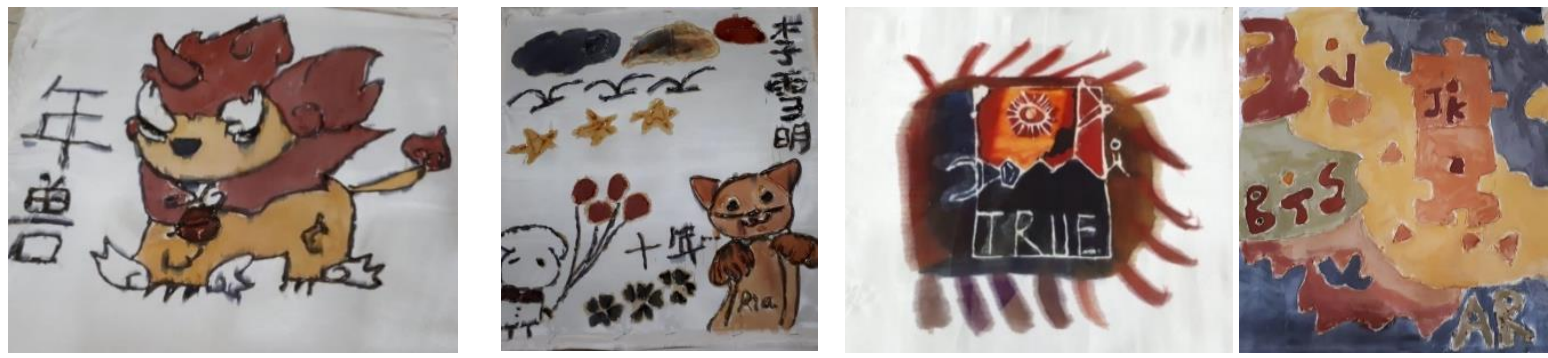

Karya lukis Batik yang memadukan antara objek dengan typo dalam bahasa mandarin ataupun bahasa Inggris. Komposisi yang divisualisasikan center dan asimetris.
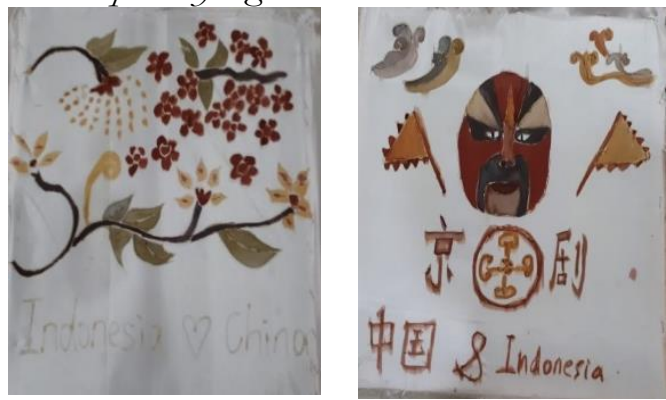

Karya lukis Batik yang memperlihatkan persababatan antara Indonesia dan China.
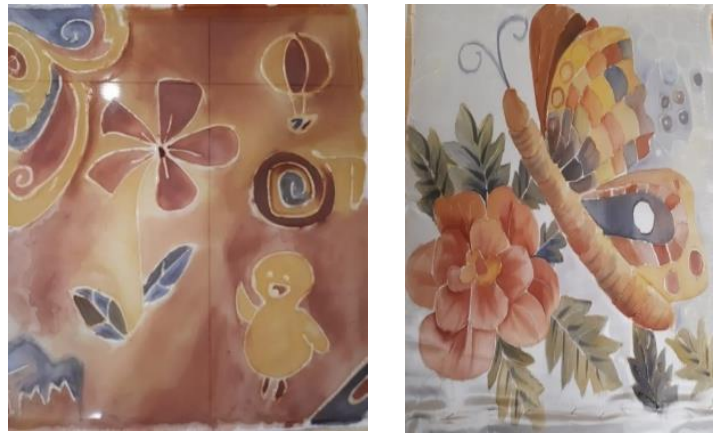

Karya lukis Batik yang memadukan antara objek flaura dan fauna dengan komposisi asimetris
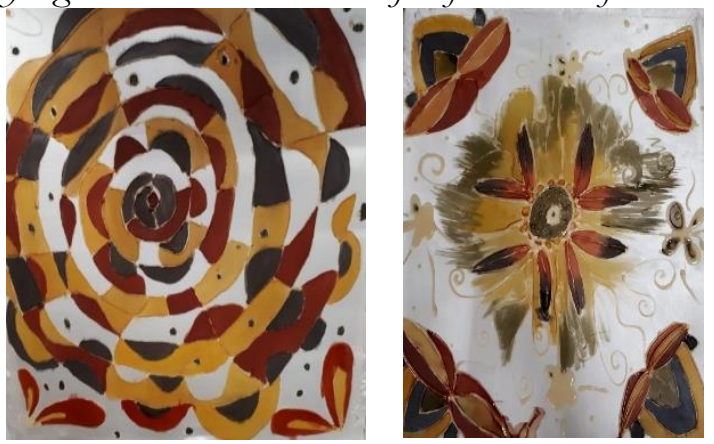

Karya lukis Batik yang memvisualisasikan objek. flaura dengan komposisi center.

Gambar 9. Sampel lukis batik yang berukuran $60 \times 60 \mathrm{~cm}$ 


\section{ENGAGEMENT}

JurnalPengabdianKepadaMasyarakat

ISSN : 2579-8375 (Print)

ISSN : 2579-8391 (Online)
This work is licensed under a Creative Commons Attribution-ShareAlike 4.0 International License. CC BY SA

\section{Pengujian Statistik}

Untuk mengetahui hasil proses pendampingan, tahap selanjutnya adalah melakukan pengujian statistik. Uji statistik disajikan dalam bentuk tabel data berdasarkan point-point dalam pertanyaan yang diedarkan dalam bentuk kuesioner. Tabel 1 menunjukkan tabel karakteristik peserta berdasarkan jenis kelamin yaitu jumlah peserta yang mengikuti kegiatan ini sebanyak 68 orang yang terdiri dari 6 orang laki- laki dan 62 orang perempuan. Tabel 2 menunjukkan karakteristik peserta berdasarkan usia yaitu usia peserta yang mengikuti kegiatan ini antara 18 tahun- 23 tahun yang terdiri dari 3 orang berusia 18 tahun, 14 orang berusia 19 tahun, 26 orang berusia 20 tahun, 22 orang berusia 21 tahun, 2 orang berusia 22 tahun dan 1 orang berusia 23 tahun.

\section{Tabel 1.}

Karakteristik Peserta Berdasarkan Jenis Kelamin

\begin{tabular}{|c|c|c|c|c|c|}
\hline & & Frequency & Percent & Valid Percent & $\begin{array}{c}\text { Cumulative } \\
\text { Percent }\end{array}$ \\
\hline Valid & Laki & 6 & 8.8 & 8.8 & 8.8 \\
\hline & Perempuan & 62 & 91.2 & 91.2 & 100.0 \\
\hline & Total & 68 & 100.0 & 100.0 & \\
\hline
\end{tabular}

Tabel 2 .

Karakteristik Peserta Berdasarkan Usia

\begin{tabular}{|l|l|l|l|l|l|}
\hline \multicolumn{2}{c}{} & Freq & $\%$ & Valid \% & Cumulative \% \\
\hline \multirow{4}{*}{ Valid } & 18 & 3 & 4.4 & 4.4 & 4.4 \\
\cline { 2 - 7 } & 19 & 14 & 20.6 & 20.6 & 25.0 \\
\cline { 2 - 6 } & 20 & 26 & 38.2 & 38.2 & 63.2 \\
\cline { 2 - 6 } & 21 & 22 & 32.4 & 32.4 & 95.6 \\
\cline { 2 - 6 } & 22 & 2 & 2.9 & 2.9 & 98.5 \\
\cline { 2 - 6 } & 23 & 1 & 1.5 & 1.5 & 100.0 \\
\cline { 2 - 6 } & Total & 68 & 100.0 & 100.0 & \\
\hline
\end{tabular}

Metode yang digunakan adalah untuk mengetahui perbedaan pengetahuan peserta sebelum mengikuti pelatihan dan setelah mengikuti pelatihan. Untuk menguji hal tersebut maka terdapat dua pengujian statistik yaitu statistik Parametrik dan Non Parametrik. Untuk menentukan pengujian statistik yang digunakan Parametrik atau Non Parametrik, maka perlu dilakukan pengujian data berdistribusi normal atau tidak menggunakan Uji Statistik. Jika KolmogorovSmirnov (K-S) dengan kriteria Sig >0.05 maka data berdistribusi normal. Tabel 3 adalah hasil Uji Normalitas dengan Kolmogorov- Smirnov (K-S). 
Tabel 3.

Uji Normalitas dengan One-Sample Kolmogorov-Smirnov Test

\begin{tabular}{|l|l|l|}
\hline \multicolumn{2}{|l|}{} & Dif \\
\hline \multirow{2}{*}{ N } & Mean & 68 \\
\hline \multirow{2}{*}{ Normal Parameters } & a,b & -2.5147 \\
\cline { 2 - 3 } & Std. Deviation & 1.92774 \\
\hline \multirow{3}{*}{ Most Extreme Differences } & Absolute & .107 \\
\cline { 2 - 3 } & Positive & .099 \\
\cline { 2 - 3 } & Negative & -.107 \\
\hline Test Statistic & .107 \\
\hline Asymp. Sig. (2-tailed) & $.054^{\mathrm{c}}$ \\
\hline
\end{tabular}

a. Test distribution is Normal.

b. Calculated from data.

c. Lilliefors Significance Correction.

Sumber: Hasil Pengolahan SPSS (2018)

Dari Tabel 3 menunjukkan Sig. sebesar 0.054 yang berarti data berdistribusi normal. Maka digunakan pengujian statistik Parametrik. Pengujian Statistik Parametrik yang digunakan dalam penelitian ini adalah Paired Samples Test dengan hipotesis sebagai berikut :

H0 : Tidak terdapat perbedaan pengetahuan peserta sebelum dan sesudah pelatihan

$\mathrm{Ha}:$ terdapat perbedaan pengetahuan peserta sebelum dan sesudah pelatihan

Kriteria penerimaan Ho dan Ha adalah jika Sig. $<0.05$ maka Ha diterima, ini berarti terdapat perbedaan pengetahuan peserta sebelum dan sesudah pelatihan sedangkan jika Sig. $>0.05$ maka Ho diterima ini berarti tidak terdapat perbedaan pengetahuan peserta sebelum dan sesudah pelatihan.

Tabel 4

Uji Paired Samples Test

\begin{tabular}{|c|c|c|c|c|c|c|c|c|c|}
\hline & & \multicolumn{5}{|c|}{ Paired Differences } & $\mathrm{t}$ & $\mathrm{df}$ & Sig. \\
\hline & & \multirow[b]{2}{*}{ Mean } & \multirow[b]{2}{*}{ Std.Dev } & \multirow{2}{*}{$\begin{array}{l}\text { Std. } \\
\text { Error } \\
\text { Mean }\end{array}$} & \multicolumn{2}{|c|}{$\begin{array}{c}95 \% \text { Confidence } \\
\text { Interval of the } \\
\text { Difference }\end{array}$} & & & \\
\hline & & & & & Lower & Upper & & & \\
\hline Pair 1 & Sblm- ssdh & -2.515 & 1.928 & .234 & -2.981 & -2.048 & $\begin{array}{c}- \\
10.757\end{array}$ & 67 & .000 \\
\hline
\end{tabular}

Sumber: Hasil Pengolahan SPSS (2018) 
Berdasarkan Tabel 4 dapat dilihat bahwa Sig. sebesar $0.00<0.05$, yang berarti terdapat perbedaan pengetahuan peserta sebelum dan sesudah pelatihan. Hal ini berarti tujuan pelatihan tercapai karena transfer knowledge berhasil. Hal ini juga didukung oleh hasil evaluasi kuesioner mengenai trainer dalam hal penguasaan materi, kejelasan penyampaian materi, kemampuan menjawab pertanyaan, interaksi dengan peserta, relevansi materi dengan kebutuhan peserta serta kesesuaian alokasi waktu dengan beban materi yang diterima. Penilaian menggunakan skala linkert dengan nilai 1 - 5 yaitu nilai 1 menyatakan Sangat Kurang, nilai 2 menyatakan Kurang, nilai 3 menyatakan Cukup, nilai 4 menyatakan Baik dan nilai 5 menyatakan Sangat Baik. Hasil evaluasi kuesioner dapat dilihat pada Tabel 5.

\section{Tabel 5}

hasil Evaluasi Kuesioner

\begin{tabular}{|c|c|}
\hline $\mathbf{N}$ & Mean \\
\hline $\mathbf{6 8}$ & 4.4289 \\
\hline
\end{tabular}

Sumber: Hasil Pengolahan SPSS (2018)

Berdasarkan Tabel 5 diperoleh nilai rata-rata hasil jawaban peserta sebesar 4.4289, ini berarti peserta sangat puas dengan kegiatan pengabdian membatik dengan material kearifan lokal.

\section{Kesimpulan}

Proses pendampingan membatik dengan menggunakan material kearifan lokal ini menjadi langkah strategis pengembangan budaya batik bagi masyarakat, baik para ibu-ibu maupun para pelajar. Hasil pengabdian ini menunjukkan bahwa proses pengabdian membatik menjadi media yang baik dalam pengembangan budaya batik serta mempererat kerjasama melalui program pertukaran budaya dan pelajar.

Selain itu, untuk mengetahui keberhasilan dari proses alih pengetahuan membatik dengan menggunakan material kearifan lokal. Maka dari data uji statistik disimpulkan bahwa data peserta proses alih pengetahuan membatik berdistribusi normal sehingga digunakan pengujian statistik Parametrik yaitu Paired Samples Test. Melalui Paired Samples Test diperoleh kesimpulan bahwa adanya perbedaan pengetahuan peserta sebelum dan sesudah pelatihan, yang berarti bahwa tujuan pelatihan tercapai karena transfer knowledge berhasil.

Selain itu hasil evaluasi kuesioner mengenai trainer dalam hal penguasaan materi, kejelasan penyampaian materi, kemampuan menjawab pertanyaan, interaksi dengan peserta, relevansi materi 


\section{ENGAGEMENT}

GurnalPengabdianKepadaMasyarakat

ISSN : 2579-8375 (Print)

ISSN : 2579-8391 (Online)
This work is licensed under a Creative Commons Attribution-ShareAlike 4.0 International License. CC BY SA

dengan kebutuhan peserta serta kesesuaian alokasi waktu dengan beban materi yang diterima.

Penilaian menggunakan skala linkert menunjukkan peserta sangat puas dengan kegiatan membatik dengan material kearifan lokal.

\section{Daftar Referensi}

Apriani, Niken. "Kecintaan Terhadap Batik Buat Niken Kembangkan Perintang Warna Dari Tepung Biji Asam." Tribunnews.Com. Last modified 2017. http://www.tribunnews.com/nasional/2017/08/08/kecintaan-terhadap-batik-buat-

niken-kembangkan-perintang-warna-dari-tepung-biji-asam.

Asikin Hasan. 'Seni Rupa Kontemporer Indonesia 'LALU, KINI [Budaya Bendawi]' Di Brussels Dan Antwerp, Belgia." Press Release : Pameran "LALU, KINI” Dalam Rangka Europalia Arts Festival Indonesia 2017, 2017.

Atmojo, Wahyu Tri. "JURNAL Pengabdian Kepada Masyarakat Vol. 19 Nomor 71 Tahun XIX Maret 2013" 19 (2013).

Dra Tity Soegiarty, M.Pd. Teknik Serti (Serti Technique) Dalam Pembelajaran Batik Tulis Di Jurusan Pendidikan Seni Rupa FPBS UPI, 2008.

Yu, Yangtao, Zhenlu Yu, Wenhua Qian, Keshi Zhang, and Dan Xu. "Visualization of Batik Cloth Based on Diffusion." In 2016 International Conference on Virtual Reality and Visualization (ICVRV), 511-515. IEEE, 2016. 